\title{
Pattern of Otolaryngological Diseases among Paediatric Population Attending ENT OPD in a Tertiary Care Centre, Dhaka
}

\author{
Afroza Khanam ${ }^{1}$, Gulshan Akhtar ${ }^{2}$, Farhana Hossain ${ }^{3}$, Nurun Nahar Chowdhury ${ }^{4}$, \\ Md. Abdur Rahman 5
}

\begin{abstract}
Background: Ear, nose and throat diseases are serious public health problems affecting all age groups. These include problem of hearing, speech, phonation, breathing, swallowing, smell and taste and protection of lower respiratory passage. Objective: There is lack of data on paediatric ENT diseases in our country and their consequences. This study was undertaken to determine the hospital prevalence of ENT diseases among paediatric population. Materials and method: This is an observational study which included 430 children presenting with ENT problem in the Department of ENT OPD, in a Tertiary Care Centre at Dhaka, Bangladesh from January 2013 to December 2013. Results: The current study was conducted among children aged 0-15 years attending ENT OPD with common otolaryngological problems. Prevalence of ENT disease was more common among male children (52.79\%) mostly belonging to $0-5$ years (male $52.86 \%$ and female $42.36 \%$ ). Vast majority of these children belonged to lower middle class family (52.32\%) with inadequacy of basic health care needs. Diseases of the ear (39.75\%) were most common followed by throat problems (33.71\%) and nasal diseases (26.51\%). Conclusion: Otitis media (acute and chronic), rhinitis and tonsillitis were most prevalent ENT disorder among the selected paediatric population. So clinicians should be familiar with these conditions to prevent potential morbidity and to create parental awareness.
\end{abstract}

Keywords: population; ENT diseases.

\section{Introduction}

Dhaka is the capital and largest city of Bangladesh. Geographically, historically, and culturally, Bangladesh forms the populous part of south Asia. The total population of this country is 163,654,860 (July 2013 estimated). Among the total population, $33 \%$ constitute the age group 0-14 years (male 27,393,912; female 26,601,199). ${ }^{1}$ Majority of admissions of
Delta Med Col J. Jan 2017;5(1):30 - 34

paediatric population in different hospitals of the country are due to respiratory illness and acute watery diarrhea. ${ }^{2}$ Morbidity pattern of this age group has several determining factors like socio-economic status, basic education, occupation of parents, socio-cultural practices, living environment, etc. ${ }^{3}$ Despite of vast improvement in health practices and various health

1. Assistant Professor, Dept. of Otolaryngology and Head Neck Surgery, Green life Medical College, Dhaka, Bangladesh.

2. Associate Professor, Dept. of Paediatrics. Green life Medical College, Dhaka, Bangladesh.

3. Assistant Professor, Dept. of Ophthalmology, Green life Medical College, Dhaka, Bangladesh.

4. Associate Professor \& Head, Dept. of Psychiatry, Green life Medical College, Dhaka, Bangladesh.

5. Junior Consultant, Medicine. DGHS. Dhaka, Bangladesh.

Correspondence: . Gulshan Akhtar. e-mail: doc.nipa@gmail.com 
facilities and awareness, various infections still remain one of the major causes of morbidity and mortality in paediatric age group. Good health is essential for overall growth and development of a child and finally determines their ability to acquire knowledge and skill. Ear, nose and throat diseases (ENT) may adversely affect this ability and are common cause of consultation to medical practitioners. According to World Health Organization (WHO), 42 million people (age $>3$ yrs) of the world have hearing loss. ${ }^{4}$ The major cause of deafness being otitis media which is second to common cold as a cause of infection in children. ${ }^{5}$ Common otolaryngological diseases in children include otitis media (acute and chronic), tonsillitis, acute laryngotracheobronchitis, adenoiditis, foreign body in ear-nose, and wax with or without fungal infection of ear, etc. Few studies have been conducted on pattern of otolaryngological diseases in paediatric age group in Bangladesh. Children often seek medical treatment for these common otolaryngological problems. Early detection of ENT problem and their accurate management may be beneficial in preventing some life threatening complications. The current study was done to determine the prevalence of ENT disorders in paediatric population and their relationship with sociodemographic factors in an urban tertiary care hospital in Dhaka, Bangladesh.

\section{Materials and method}

This is an observational study conducted at a tertiary hospital, Dhaka, Bangladesh. During the study period January 2013 - December 2013 (one calendar year), total number of 1600 patients attended ENT OPD and among them 430 patients were children aged between $0-15$ years presenting with ear, nose and throat diseases. Children with suspected neoplasm were excluded from the study. The study population was evaluated by history and complete ENT examination. Statistical analysis was done using frequency and percentage.

\section{Results}

Total number of 430 children (0-15 yrs) presenting with ENT problem at ENT OPD, tertiary hospital, Dhaka during the study period of one year were included in the study. In the current study, overall ENT diseases were found more common in male children $(52.79 \%)$ than female children $(47.20 \%)$. This sex difference does not correlate with other studies. Majority (52.32\%) of the study population were from lower middle class, living in unhygienic environment with large family size and poor sanitation. The study showed that, diseases of ear $(39.75 \%)$ were most common ENT problem among the study population followed by tonsillitis $(15.34 \%)$, rhinitis $(6.97 \%)$, enlarged adenoids (6.51\%) and epistaxis (4.65\%).

\section{Ear disorder}

Aural disorder is common in children due to anatomical variation of Eustachian tube (wider, shorter and straighter in children in comparison with adults) that leads to easy entrance and colonization of pathogenic organism from nose and pharynx to middle ear. Otalgia was the most common presenting complaint of majority of the ear problem followed by ear discharge and impaired hearing. Otitis media with effusion (24.18\%) was the most common ear problem followed by wax $(6.27 \%)$. Fluid in the middle ear with mild to moderate hearing loss was seen among 5.58\% study population. Foreign body in ear was seen among $1.86 \%$ children. Other ear problems included trauma to the ear, fungal infection, congenital malformation which constitutes $1.86 \%$.

\section{Nose disorder}

Among nasal disorders, rhinitis (6.97\%) was the commonest problem followed by sinusitis $(5.34 \%)$, epistaxis $(4.65 \%)$ and foreign body (1.39\%). Rhinitis was associated with upper 
respiratory tract infection and was infective in nature. Rhinorrhoea and nasal obstruction were the common presenting complaints of these nose disorders.

Table I: Demographic characteristics $(\mathrm{N}=430)$

\begin{tabular}{lcc}
\hline Characteristics & Frequency & Percentage \\
\hline Gender & & \\
Male (n=227; 52.79\%) & & \\
$\quad$ 0-5 years & 120 & 52.86 \\
$\quad$ 6-10 years & 70 & 30.83 \\
$\quad$ 11-15 years & 37 & 16.29 \\
Female (n=203; 47.20\%) & & \\
0-5 years & 86 & 42.36 \\
$\quad$ 6-10 years & 62 & 30.54 \\
11-15 years & 55 & 27.09 \\
Socioeconomic status & & \\
Upper class & 10 & 2.32 \\
Upper middle class & 50 & 4.62 \\
Middle class & 100 & 23.25 \\
Lower middle class & 225 & 52.32 \\
Lower class & 45 & 10.46 \\
\hline
\end{tabular}

Table II: Distribution of ENT diseases among study population $(\mathrm{N}=430)$

\begin{tabular}{|c|c|c|c|c|c|}
\hline Disorders & ENT Disorders & Male & Female & Total & Percentage \\
\hline \multirow{6}{*}{ Ear Diseases } & $\begin{array}{l}\text { Otitis media (acute and } \\
\text { chronic) }\end{array}$ & 60 & 44 & 104 & 24.18 \\
\hline & $\begin{array}{l}\text { Otitis media with } \\
\text { effusion }(\mathrm{OME})\end{array}$ & 14 & 10 & 24 & 5.58 \\
\hline & Wax & 13 & 14 & 27 & 6.27 \\
\hline & Foreign body & 5 & 3 & 8 & 1.86 \\
\hline & Others & 6 & 2 & 8 & 1.86 \\
\hline & $\begin{array}{l}\text { Total no. of patient with } \\
\text { ear diseases }\end{array}$ & 98 & 73 & 171 & 39.75 \\
\hline \multirow{7}{*}{ Nose Diseases } & Rhinitis & 12 & 18 & 30 & 6.97 \\
\hline & Sinusitis & 10 & 13 & 23 & 5.34 \\
\hline & Epistaxis & 12 & 8 & 20 & 4.65 \\
\hline & DNS & 3 & 2 & 5 & 1.16 \\
\hline & Foreign body & 5 & 1 & 6 & 1.39 \\
\hline & Others & 3 & 2 & 5 & 1.16 \\
\hline & $\begin{array}{l}\text { Total no. of patient with } \\
\text { nose diseases }\end{array}$ & 61 & 53 & 114 & 26.51 \\
\hline \multirow{8}{*}{ Throat diseases } & Tonsillitis & 30 & 36 & 66 & 15.34 \\
\hline & Pharyngitis & 18 & 11 & 29 & 6.74 \\
\hline & Enlarged adenoids & 16 & 12 & 28 & 6.51 \\
\hline & $\begin{array}{l}\text { Acute laryngo trachea } \\
\text { bronchitis (ALTB) }\end{array}$ & 16 & 19 & 25 & 5.89 \\
\hline & Foreign body & 1 & 0 & 1 & 0.23 \\
\hline & Fungal infection & 4 & 6 & 10 & 2.32 \\
\hline & Others & 5 & 6 & 11 & 2.55 \\
\hline & $\begin{array}{l}\text { Total no. of patient with } \\
\text { throat diseases }\end{array}$ & 74 & 71 & 145 & 33.72 \\
\hline
\end{tabular}

\section{Throat disorder}

Common throat problem found among our study population in decreasing order of frequency were tonsillitis $(15.34 \%)$, pharyngitis $(6.74 \%)$, enlarged adenoids (6.51\%), ALTB (5.89\%) and others $(2.55 \%)$. The majority of study population with throat disease presented with sore throat. Foreign body in the throat was found only in $0.23 \%$ of children.

\section{Discussion}

In Bangladesh, common diseases of paediatric age group are malnutrition, ARI, diarrhoea, measles, malaria and other infectious diseases. ENT disorders may accompany these diseases or may occur independently. Though the government of Bangladesh has launched various health related programmes which work by early detection and appropriate intervention of common health problems among children, ENT diseases still remain one of the major cause of chronic morbidity due to lack of awareness among general population and parents. The current study was conducted among total 430 children aged 0 to 15 years presenting with ENT problems at ENT OPD, in a tertiary hospital of Dhaka in one calendar year. In the current study, overall ENT diseases were found more common in male children $(52.79 \%)$ than female children (47.20\%). This sex difference does not correlate with other studies. ${ }^{6}$ Otitis media (acute and chronic) and otitis media with effusion are the most common morbid conditions of the ear which if not treated accurately may lead to deafness. This high prevalence of otitis media in our study corresponds with that of other studies. ${ }^{7}$ Among 430 study population 171 (39.75\%) children presented with ear problems and the prevalence was more among male $(n=60)$ than female $(n=44)$ children. This result correlates with studies done previously. ${ }^{8}$ In our study, among 171 children with ear diseases $24(5.58 \%)$ had otitis media with effusion, 27 (6.27\%) had impacted wax, 8 (1.86\%) 
presented with foreign body in ear and other ear problems constitute $1.86 \%$ which consisted of trauma to the ear, fungal infection and congenital malformation. In a developing country like Bangladesh, poor socioeconomic condition, large family size, living in overcrowded area, poor sanitation, lack of provision of health care facilities and most importantly lack of awareness among parents regarding the grievous consequences of recurrent ear infection leads to chronic ear problem and ultimately deafness. So awareness of the disease among general population, their knowledge when and where to seek medical help, early detection and appropriate intervention of these problems will enhance to a greater extent to minimize or even prevent long term complications of common ear problems.

Young children particularly $<5$ yrs old have immature immune system and are prone to infection. Acute otitis media (AOM) is a common complication of upper respiratory tract infection whose pathogenesis involves both viruses and bacteria. $^{9}$ In children, common presenting complaint of nose disorders is nasal obstruction and rhinorrhoea. These symptoms are commonly produced by rhinitis, allergy, naso pharyngitis and tonsillo adenoiditis. Our study showed, rhinitis $(6.97 \%)$ was the commonest problem followed by sinusitis $(5.34 \%)$, epistaxis $(4.65 \%)$ and foreign body $(1.39 \%)$. Chronic or recurrent tonsillo adenoiditis require surgical intervention otherwise these children develop chronic nasal obstruction symptom or obstructive sleep apnea (OSA). ${ }^{10}$ Consequences of untreated paediatric OSA are snoring during sleep, poor quality of sleep, day time drowsiness or sleepiness, inattention, hyperactivity, irritability, abnormal urine production at night, adenoid facies, and failure to thrive. ${ }^{11}$ To minimize or prevent these complications, proper diagnosis at early stage and appropriate intervention is necessary. Epistaxis in young children is also a common problem which is usually due to local trauma in Kiesselbach's plexus. The underlying cause of epistaxis is local inflammatory lesion, infection, trauma usually by nose pricking. ${ }^{12}$ Most of bleeding is self limiting. There is scanty availability of data on prevalence of epistaxis in children. In current study 20 $(4.65 \%)$ children presented with epistaxis and the prevalence was more among male.

Among throat infection acute and chronic tonsillitis is the commonest throat problem usually occurring in children aged 3-15 years. ${ }^{13}$ The prevalence of tonsillitis in our study was 66 $(15.43 \%)$ which is on the top of the list among throat problem. Tonsillitis was followed by pharyngitis (6.74\%), enlarged adenoids (6.51\%), ALTB (5.89\%), accidental ingestion of foreign body in throat $(0.23 \%)$, fungal infection $(2.32 \%)$ and others. Bacterial infection and some immunological factors lead to chronic tonsillitis and its complications. Common pathogens responsible are streptococcus pyogens and beta hemolytic streptococci. During acute attack of tonsillitis if accurate management is not done then it leads to the following complications like: acute rheumatic fever, acute post streptococcal glomerulonephritis, peritonsillar abscess, and septicemia. ${ }^{14}$ For the reason, accurate diagnosis at early phase of the disease and appropriate antimicrobial treatment as per required will promote to a greater extent to prevent the afore mentioned long term complications.

\section{Conclusion}

The current study suggests that, otitis media (acute and chronic), rhinitis and tonsillitis are most prevalent ENT disorder among paediatric study population presenting to ENT OPD during the study period. These acute problems if not diagnosed and managed accurately lead to chronic or recurring symptoms and ultimately either require surgical intervention or produce chronic morbidity. So medical practitioners who commonly deal with these problems can play an 
important role in creating awareness among the parents how to overcome or when to seek for medical help and thereby reduce the prevalence of morbidity these common ENT problems produce.

\section{References}

1 Index Mundi [Internet]. Bangladesh Demographic Profile. 2013 (cited 2014 march 22). Available from: http://www.indexmundi.com/bangladesh/.

2. Hasan MS, Barua ST, Mahmud MN, Kamal AHM, Enayetullah M, Karim MR. Disease Profile and Death Pattern among Children Admitted in a Medical College Hospital. Bangladesh J Child Health. 2012;36(2):66-67.

3. Roy E, Hasan KZ, Richards JL, Haque AKMF, Siddique AK, Sack RB. Burden and Outcome of Acute Otitis Media in Rural Bangladesh. S A Journal of child health. 2012; 6(4):118-22.

4. Morris PS, Leach AJ. Acute and Chronic Otitis Media. Paediatric Clin North America. 2009;56(6):1383-99.

5. Kishve SP, Kumar N, Kishve PS, Arif SMM, Kalakoti P. Ear, Nose and Throat Disorders in Paediatric Patients at a Rural Hospital in India. AMJ. 2010;3(12):786-90.
6. Shaheen MM, Raquib A, Ahmad SM. Chronic Suppurative Otitis Media and Its Association with Socieo Economic Factors among Rural Primary School Children of Bangladesh. Indian J Otolaryngology Head Neck Surgery. 2012;64(1):36-41.

7. Sophia A, Isaac R, Rebekah G, Brahmadath K, Rupa V. Risk Factors for Otitis Media among Preschool Rural Indian Children. Int J Paediatric Otolaryngology. 2010;74(6):677-83.

8. Kliegman RM, Jenson HB, Behrman RE, Stanton BF, editors. Nelson Textbook of Pediatrics. 18th ed. Philadelphia (PA): Elsevier; 2007. p.1795-99.

9. Pettigrew MM, Gent JF, Pyles RB, Miller AL, Nokso-Koivisto J, Chonmaitree T. Viral-Bacterial Interactions and Risk of Acute Otitis Media Complicating Upper Respiratory Tract Infection. J Clin Microbiol. 2011;49(11):3750-55.

10. Ahn YM. Treatment of Obstructive Sleep Apnea in Children. Korean J Pediatr. 2010;53(10):872-79.

11. Vikram VJ, Prasad T, Sahoo GC. Etiology and Management of Epistaxis in Children. Journal Otolaryngology. 2014;4(1):20-26.

12. Kvestad E, Kvererner KJ, Roysamb E, Tambs K, Harris JR, Magnus P. Heritability of Recurrent Tonsillitis. Arch Otolaryngology Head Neck Surgery. 2005;131(5):383-87.

13. Dhingra PL. Diseases of Ear Nose and Throat. 6th ed. Phipadelphia (PA): Elsevier; 2007. 